\title{
PARP Inhibitor E7016
}

National Cancer Institute

\section{Source}

National Cancer Institute. PARP Inhibitor E7016. NCI Thesaurus. Code C91387.

An inhibitor of the nuclear enzyme poly(ADP-ribose) polymerase (PARP) with potential chemo- and/or radiosensitizing activity. PARP inhibitor E7016 selectively binds to PARP and prevents PARP mediated DNA repair of single strand DNA breaks via the baseexcision repair pathway. This enhances the accumulation of DNA strand breaks and promotes genomic instability and eventually leads to apoptosis. In addition, this agent may enhance the cytotoxicity of DNA-damaging agents and reverse tumor cell resistance to chemotherapy and radiation therapy. PARP catalyzes post-translational ADP-ribosylation of nuclear proteins that signal and recruit other proteins to repair damaged DNA and is activated by single-strand DNA breaks. 